\title{
Is it time for a lifestyle approach to the burden of chronic kidney disease?
}

\author{
Sarah White \\ Hypertension Research (2013) 36, 295-296; doi:10.1038/hr.2012.190; published online 13 December 2012
}

$\mathrm{P}$ roteinuria is the prime manifestation of chronic kidney disease (CKD), and is associated with significantly elevated cardiovascular morbidity and mortality, in addition to progression to end-stage kidney disease (ESKD). ${ }^{1}$ Primary prevention of proteinuria therefore has significant implications both for the future burden of ESKD, and for cardiovascular outcomes in the general population. In this issue of Hypertension Research, Wakasugi et al. ${ }^{2}$ examine the effect of a healthy lifestyle on the 1-year risk of incident proteinuria in a cohort of 4902 adults aged 40-79 years who participated in the Specific Health Checkups and Guidance System program conducted in Sado city, Japan, in 2008. A 'healthy lifestyle score' was calculated based on smoking status, body mass index, alcohol consumption, exercise and eating patterns. The authors found that participants with the healthiest lifestyle score, that is, nonsmokers, with a body mass index $<25 \mathrm{~kg} \mathrm{~m}^{-2}$, consuming $<20 \mathrm{~g}$ of alcohol per day on average, participating in regular exercise and not in the habit of skipping breakfast or snacking at nighttime, were at significantly lower 1-year risk of developing proteinuria. This result was independent of diabetes, hypertension and hypercholesterolemia status at baseline. Wakasugi et al. estimate that as much as $47 \%$ of the cases of incident proteinuria in their cohort may be attributed to a lack of adherence to a healthy lifestyle pattern, and their findings strongly support the efficacy of lifestyle intervention as a response to the burden of

S White is at University of Michigan, 1415 Washington Heights, Suite 3645A SPH I, Ann Arbor, MI 481092029, USA

E-mail: slwh@med.umich.edu morbidity and mortality associated with CKD.

A particularly salient feature of the cohort study by Wakasugi et al. is the demographic profile of the population in which it was carried out. Sado city in Niigata Prefecture has one of the most rapidly aging populations in Japan, with $>35 \%$ of the population aged 65 years or older, compared with the current national figure of $\sim 25 \%$ of the total population aged $>65$ years. The demographic distribution of Sado city therefore resembles the projected population of Japan in 2039. With a median age of 41 years, Japan's population is currently the world's oldest; however, it is by no means unique in its demographic transition: rapidly aging populations are also found in Greece, Austria, Czech Republic, Slovenia and Italy, and by 2050 Spain is projected to replace Japan as the country with the world's oldest population with a median age of 55 years. $^{3}$

Responding to the escalating burden of chronic diseases that accompany rapid population aging is the greatest challenge currently facing health service providers in highincome countries and, increasingly, middleto-low income countries. Disease prevention is an imperative: with an aging population the working-age population and the tax base are diminished, thus shrinking the existing revenues available to fund public resources, while at the same time health systems must increasingly meet the long-term care needs of an expanding older population with more complex chronic disease. The progressive decline over recent years in the potential support ratio- that is, the number of economically active individuals in the population compared with the number of beneficiaries of health and pension fundshas been well-described for Japan and countries with similar demographic profiles. ${ }^{3}$ Given that the number of working-age people in Japan is projected to continue to decline for the next 50 years, ${ }^{4}$ this means that the government will be required to support a steadily growing elderly population with increasingly resource-intensive care needs, even as the population of taxpayers is shrinking. To avoid a point of crisis, this trend will need to be met with both fiscal and health policies, directed at mitigating the costs of care and incorporating wideranging health and social interventions designed to support healthy aging.

The costs associated with the treatment of ESKD in Japan, and the successive costcontainment policies that have been implemented over the past three decades, provide a clear example of the unsustainable costs that may be associated with an escalating population burden of chronic disease. In 2010, the number of dialysis patients in Japan was 289415 (2260 per million population)more patients per head of population than any other country with the exception of Taiwan. ${ }^{5}$ The incidence of ESKD has increased steadily at $\sim 1.6 \%$ per annum for the past decade, driven by an aging population and in particular by a growing incidence of diabetic nephropathy, which accounted for $43.9 \%$ of primary diagnoses among new ESKD patients in 2010. Overall, the prevalent dialysis population grew by nearly 30\% between 2001 and 2010. Until population aging peaks as projected in 2040, the prevalent ESKD population can be expected to see corresponding growth unless primary and secondary prevention are able to curb these trends (Figure 1).

With an annual estimated expenditure per ESKD patient of US $\$ 41,681$ (purchasing power parity, 2003), the costs of hemodialysis 


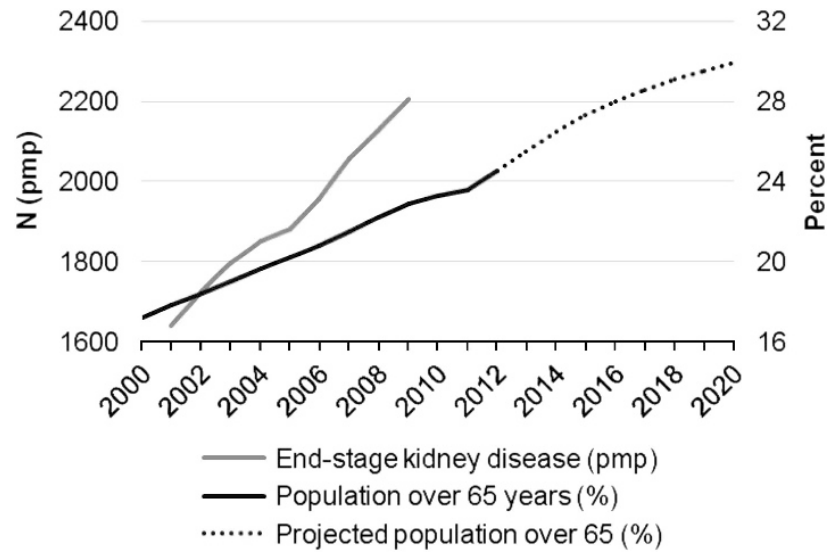

Figure 1 Growth in the prevalence of ESKD in Japan, compared with growth of the population aged $>65$ years.

in Japan are low in relation to those of comparable economies due to stringent cost-cutting policies in effect between 1980 and $2000 .{ }^{6}$ However, the continued growth of the ESKD population prompted additional reimbursement cuts in 2002 and again in 2006, increasing patient copayments and the cost-to-reimbursement margin for providers to the extent that private facilities, which provide $\sim 80 \%$ of maintenance hemodialysis, may in some cases be required to operate at a loss. ${ }^{6}$ Clearly, there is a threshold at which reimbursement cuts will begin to affect access to treatment and quality of care, and therefore cost-containment policies must also encompass a commitment to disease prevention and more cost-effective modalities of renal replacement therapy, such as kidney transplantation, which remains rare in Japan.

The findings of Wakasugi et al. point to a potentially cost-effective approach to CKD prevention that is consistent with a broader approach to the prevention of chronic cardiovascular diseases. However, whereas the evaluation of screening and pharmacological interventions for cost-effectiveness is relatively straight-forward, it is more difficult to establish scientific evidence for lifestylerelated interventions, and determining an optimal approach to the promotion of healthy lifestyles at the population level is likely to necessitate wide intersectoral consultation. In a recent review of the efficacy of population interventions aimed at improving dietary habits, increasing physical activity and reducing tobacco use, ${ }^{6}$ the American Heart Association found that the strategies most effective in promoting lifestyle change included media campaigns, mandated food labeling, subsidies and taxation to lower the cost of healthy foods and increase the cost of harmful products, multi-component school and workplace programs, urban planning to promote physical activity and improve access to supermarkets, restrictions on advertizing and sales, and food standards. Significantly, the AHA review observed that individual interventions might not have an impact when implemented in isolation. By contrast, community and national programs that used education and media campaigns as part of a multi-component intervention that also included government-mandated economic incentives and changes to the physical environment were able to effect significant improvements in lifestyle behaviors and health outcomes. ${ }^{7,8}$ Although cultural, political and economic factors will affect the applicability and impact of specific interventions in one country relative to another, it seems clear that the greatest gains will be made when there is broad intersectoral support for the goal of lifestyle improvement. ${ }^{9}$

Wakasugi et al. conclude that close to half of the incident proteinuria in their cohort was attributable to lifestyle-related risk factors that might be readily amenable to non-pharmalogical interventions. The implications of these findings extend beyond high-income countries: the demographic transition of the twentieth century toward lower fertility, higher life expectancy and commensurately older populations is now a global phenomenon shaping the disease burden in low- and middle-income countries. As in Japan, this has reduced the availability of family members to support older generations, and may produce particularly acute consequences in settings where social support systems are undeveloped. Moreover, as the rate of demographic change is fastest in low- and middle-income countries, there will be less time to make the policy adjustments necessary to meet the needs of these populations. ${ }^{3}$ Chronic disease prevention is a global imperative, and healthy aging through lifestyle improvement, facilitated by governmental support and conducive social policies, is central to this goal.

1 Astor BC, Matsushita K, Gansevoort RT, van der Velde M, Woodward M, Levey AS, Jong PE, Coresh JChronic Kidney Disease Prognosis Consortium Astor BC, Matsushita K, Gansevoort RT, van der Velde M, Woodward M, Levey AS, de Jong PE, Coresh J, El-Nahas M, Eckardt KU, Kasiske BL, Wright J, Appel L, Greene T, Levin A, Djurdjev O, Wheeler DC, Landray MJ, Townend JN, Emberson J, Clark LE, Macleod A, Marks A, Ali T, Fluck N, Prescott G, Smith DH, Weinstein JR, Johnson ES, Thorp ML, Wetzels JF, Blankestijn PJ, van Zuilen AD, Menon V, Sarnak M, Beck G, Kronenberg F, Kollerits B, Froissart M, Stengel B, Metzger M, Remuzzi G, Ruggenenti P, Perna A, Heerspink HJ, Brenner B, de Zeeuw D, Rossing $\mathrm{P}$, Parving $\mathrm{HH}$, Auguste $\mathrm{P}$, Veldhuis K, Wang Y, Camarata L, Thomas B, Manley $\mathrm{T}$. Lower estimated glomerular filtration rate and higher albuminuria are associated with mortality and end-stage renal disease. A collaborative meta-analysis of kidney disease population cohorts. Kidney Int 2011; 79: 1331-1340.

2 Wakasugi M, Kazama JJ, Yamamoto S, Kawamura K Narita I. A combination of healthy lifestyle factors is associated with a decreased incidence of chronic kidney disease: a population-based cohort study. Hypertens Res 2013; 36: 328-333.

3 World Population Ageing 1950-2050. Population Division, Department of Economic and Social Affairs United Nations New York 2002.

4 National Institute of Population and Social Security Research. http://www.ipss.go.jp/pp-newest/j/newest03/ h3_3.html. Accessed 30 September 2012.

5 US Renal Data System, USRDS 2012 Annual Data Report: Atlas of Chronic Kidney Disease and End-Stage Renal Disease in the United States, National Institutes of Health, National Institute of Diabetes and Digestive and Kidney Diseases: Bethesda, MD, 2012.

6 Mozaffarian D, Afshin A, Benowitz NL, Bittner V, Daniels SR, Franch HA, Jacobs Jr DR, Kraus WE, Kris-Etherton PM, Krummel DA, Popkin BM, Whitsel LP, Zakai NA. Population approaches to improve diet, physical activity, and smoking habits: a scientific statement from the american heart association. Circulation 2012; 126: 1514-1563.

7 Pekka P, Pirjo P, Ulla U. Influencing public nutrition for noncommunicable disease prevention: from community intervention to national programme: experiences from Finland. Public Health Nutr 2002; 5 . 245-251.

8 Puska P, Stahl T. Health in all policies: the Finnish initiative: background, principles, and current issues. Annu Rev Public Health 2010; 31: 315-328.

9 Adelaide Statement on Health in all Policies. World Health Organization, Geneva, 2010, Available from http://www.who.int/social_determinants/hiap statement_who_sa_final.pdf. 